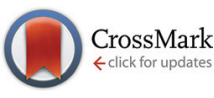

Cite this: Org. Chem. Front., 2016, 3 339

Received 3rd November 2015, Accepted 27th December 2015

DOI: $10.1039 / c 5 q 000346 f$

rsc.li/frontiers-organic

\title{
Enantioselective dearomative [3 + 2] cycloadditions of indoles with azomethine ylides derived from alanine imino esters $\uparrow$
}

\begin{abstract}
Anthony L. Gerten and Levi M. Stanley*
Catalytic, enantioselective [ $3+2]$ cycloadditions of azomethine ylides derived from alanine imino esters with 3-nitroindoles are reported. The dearomative cycloaddition reactions occur in the presence of a catalyst generated in situ from $\mathrm{Cu}(\mathrm{OTf})_{2}$ and $(R)$-Difluorphos to form exo'-pyrroloindoline cycloadducts and establish four contiguous stereogenic centers, two of which are fully substituted. The exo'-pyrroloindoline products are formed in moderate-to-good yields (39-85\%) with high diastereoselectivities (up to $98: 1: 1 \mathrm{dr}$ ) and enantioselectivities (up to $96 \%$ ee)
\end{abstract}

Department of Chemistry, Iowa State University, Ames, IA 50011, USA.

E-mail: lstanley@iastate.edu

$\dagger$ Electronic supplementary information (ESI) available: Experimental procedures and characterization data for new compounds, and crystallographic data (CIF) for compound 3f.HBr. CCDC 1434459. For ESI and crystallographic data in CIF or other electronic format see DOI: 10.1039/c5qo00346f

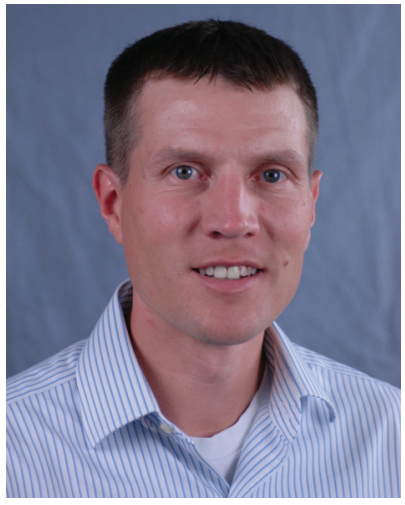

Levi M. Stanley
Levi Stanley received his B.A. in chemistry from Augustana College (SD) in 2001, where he worked with Professors Gary Earl and Jetty Duffy-Matzner. In 2002, he began his graduate studies with Professor Mukund P. Sibi at North Dakota State University, where he developed enantioselective dipolar cycloadditions and studied applications of chiral relay ligands and auxiliaries in enantioselective catalysis. He received his Ph.D. in 2007 and joined professor John F. Hartwig's group at the University of Illinois as an NIH Postdoctoral Fellow. His work in the Hartwig group focused on the development of iridium-catalyzed allylic substitution reactions. In 2011, he joined the faculty at Iowa State University in the Department of Chemistry. Areas of research interest include catalysis, synthetic organic chemistry, and heterocyclic chemistry.

\section{Introduction}

The development of dearomatization reactions offers the potential to rapidly generate molecular complexity and new molecular frameworks. ${ }^{1}$ In recent years, $[2+2],{ }^{2}[3+2],{ }^{3}$ $[4+2],{ }^{4}$ and $[5+2]^{5}$ dearomative cycloadditions have emerged as promising strategies to construct polycyclic carbocycles and heterocycles from arenes and heteroarenes. Despite the steady development of new dearomative cycloadditions reactions, examples of catalytic, enantioselective dearomative cycloadditions are limited. ${ }^{2 a, 3 e, g-i}$

Among the promising classes of dearomative cycloadditions for further development are intermolecular $[3+2]$ cycloadditions of nitrogen-containing 1,3-dipoles with arenes and heteroarenes. In particular, cycloadditions of azomethine ylides with arenes and heteroarenes have emerged as a viable approach to generate polycyclic nitrogen heterocycles. ${ }^{6}$ Gribble and co-workers initially reported cycloadditions of unstabilized azomethine ylides with 2- and 3-nitroindoles to form racemic pyrroloindolines. ${ }^{7}$ More recently, Chataingner, Piettre, and co-workers showed that cycloadditions of unstabilized azomethine ylides with electron-deficient arenes and heteroarenes form a wide variety of racemic, polycyclic cycloadducts in good-to-excellent yields. ${ }^{8}$

In 2014, Awata and Arai reported the first catalytic, enantioselective dearomative cycloadditions of stabilized azomethine ylides with 3-nitroindoles. ${ }^{9}$ Cycloadditions of a wide range of azomethine ylides derived from glycine imino esters occur with excellent enantioselectivity and nearly perfect exo'-selectivity when the reactions are run in the presence of a complex prepared from $\mathrm{Cu}(\mathrm{OTf})_{2}$ and a chiral PyBidine ligand. However, catalytic, enantioselective dearomative cycloadditions of azomethine ylides derived from alanine imino esters have 


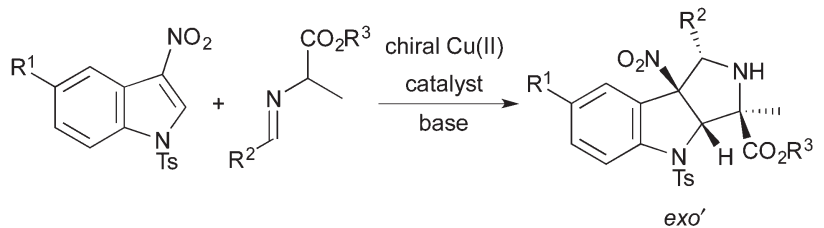

Scheme 1 Enantioselective cycloadditions of 3-nitroindoles with alanine-derived azomethine ylides.

not been reported. Herein, we report the first examples of diastereo- and enantioselective dearomative cycloadditions of alanine-derived azomethine ylides with 3-nitroindoles. These reactions generate pyrroloindolines with four contiguous stereogenic centers, two of which are fully substituted (Scheme 1).

\section{Results and discussion}

To identify a diastereo- and enantioselective catalyst for dearomative cycloadditions of alanine-derived azomethine ylides, we evaluated the model reaction of $N$-tosyl-3-nitroindole 1a with racemic imino ester $\mathbf{2 a}$ (Table 1). Initially, we found that copper(II) triflate complexes of the chiral bisphosphine ligands $(R)$-BINAP, $(R)$-Segphos, and $(R)$-Difluorphos (10 mol\%) catalyzed the cycloadditions of 1a with $2 \mathrm{a}$. These reactions formed a diastereomeric mixture of cycloadducts $3 \mathbf{a}$ with exo'-3a generated as the major diastereomer (entries 1-3). The reaction of 1a and 2a occurred with the highest diastereoselectivity (93:3:4 exo'-3a:exo-3a:endo-3a) with the copper(II) triflate complex of $(R)$-difluorophos as catalyst (entry 3$).{ }^{10}$ The cycloadduct $e x o^{\prime}-3$ a was isolated in $73 \%$ yield with $86 \%$ ee. The high enantioselectivity and diastereoselectivity observed for the model reaction led us to explore additional reaction parameters using the combination of $\mathrm{Cu}(\mathrm{OTf})_{2}$ and $(R)$-difluorphos as catalyst.

By lowering the reaction temperature to $0{ }^{\circ} \mathrm{C}$ and $-20{ }^{\circ} \mathrm{C}$, we observed higher enantioselectivity for $\operatorname{exo}^{\prime}-\mathbf{3 a}$ (92-93\% ee) with lower diastereoselectivity (entries 4 and 5). For example, the reaction of $1 \mathrm{a}$ with $2 \mathrm{a}$ forms a $41: 15: 44$ mixture of $e x o^{\prime}$ : exo: endo diastereomers when the reaction is carried out at $-20{ }^{\circ} \mathrm{C}$. The endo selectivity of the reaction carried out at

Table 1 Identification of catalysts and reaction conditions for the cycloaddition of $1 \mathrm{a}$ and $2 \mathrm{a}^{\mathrm{a}}$

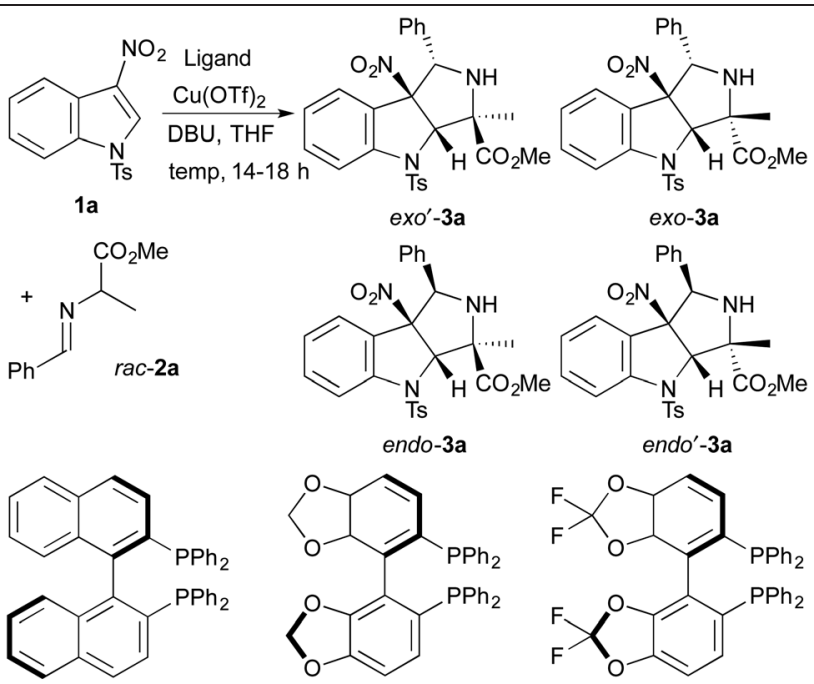

(R)-BINAP L1

(R)-Segphos L2

(R)-Difluorphos L3

\begin{tabular}{|c|c|c|c|c|c|c|}
\hline Entry & Ligand & Temp $\left({ }^{\circ} \mathrm{C}\right)$ & Equiv. 2a & $\begin{array}{l}\mathrm{dr} \\
\text { exo }^{\prime}: \text { exo }: \text { endo }^{b}\end{array}$ & Yield exo'-3a $a^{c}(\%)$ & $\begin{array}{l}\text { exo } \\
e x a^{d}(\%)\end{array}$ \\
\hline 1 & L1 & $\mathrm{rt}$ & 1.0 & $55: 19: 26$ & 35 & 60 \\
\hline 2 & L2 & $\mathrm{rt}$ & 1.0 & $79: 9: 12$ & 60 & 82 \\
\hline 3 & L3 & $\mathrm{rt}$ & 1.0 & $93: 3: 4$ & 73 & 86 \\
\hline 4 & L3 & 0 & 1.0 & $73: 9: 18$ & 51 & 92 \\
\hline 5 & L3 & -20 & 1.0 & $41: 15: 44$ & 34 & 93 \\
\hline $6^{e}$ & L3 & $\mathrm{rt}$ & 1.0 & $71: 11: 18$ & 58 & 76 \\
\hline 7 & L3 & $\mathrm{rt}$ & 1.2 & $93: 3: 4$ & 75 & 89 \\
\hline 8 & L3 & $\mathrm{rt}$ & 1.5 & $92: 3: 5$ & 78 & 88 \\
\hline 9 & L3 & $\mathrm{rt}$ & 2.0 & $92: 3: 5$ & 72 & 90 \\
\hline
\end{tabular}

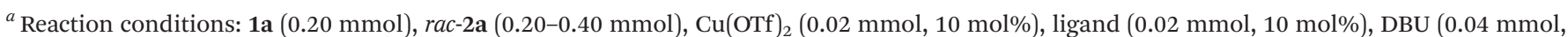

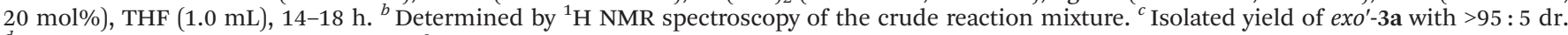

${ }^{d}$ Determined by chiral HPLC analysis. ${ }^{e}$ Reaction conducted with 5 mol\% of the Cu catalyst. 
$-20{ }^{\circ} \mathrm{C}$ led us to postulate that the model cycloaddition is endo-selective, but epimerization of endo-3a to exo'-3a occurs at higher temperatures through a retro-Mannich/Mannich addition pathway and leads to the observed $e x o^{\prime}$-selectivity. ${ }^{11}$

Lowering the loading of the copper catalyst also proved detrimental to the diastereo- and enantioselectivity of the model reaction. The reaction of $1 \mathrm{a}$ with $2 \mathrm{a}$ in the presence of $5 \mathrm{~mol} \%$ of the copper catalyst formed $3 \mathrm{a}$ as a $71: 11: 18$ mixture of exo' : exo : endo diastereomers with $e^{\prime} o^{\prime}-3 a$ isolated in $76 \%$ ee (entry 6). The decrease in enantioselectivity and diastereosectivity observed at lower catalyst loading suggests: (1) the rate of uncatalyzed background reaction is likely competitive with the rate of the catalyzed process; and (2) the copper complex may catalyze the epimerization of endo-3a to exo'-3a.

Varying the concentration of imino ester $\mathbf{2 a}$ has minimal impact on the yield and selectivity of the model reaction (compare entries 3 and 7-9). The diastereoselectivity remains essentially unchanged when varying the amounts of imino ester 2a from 1.0-2.0 equivalents. However, a slight excess (1.2 equivalents, entry 7) of 2 a leads to a modest increase in enantioselectivity, but this trend does not hold when the concentration of $2 \mathbf{a}$ is further increased (entries 8 and 9).

To develop a better understanding of the rates of the catalyzed reaction and the uncatalyzed background reaction and the evolution of the diastereoselectivity over time, we conducted cycloadditions of $\mathbf{1 a}$ with $\mathbf{2 a}$ in the presence and absence of copper catalyst and monitored the yield and diastereoselectivity over time (Table 2 ). The catalyzed reaction of 1a with 2a occurs to approximately 90\% conversion after $2 \mathrm{~h}$ (entry 1) and is complete after $6 \mathrm{~h}$ (entry 3), while the uncatalyzed reaction occurs to approximately 50\% and $80 \%$ conver-

Table 2 Evolution of stereoselectivity in catalysed versus uncatalysed reactions of $1 a$ with $2 a^{a}$

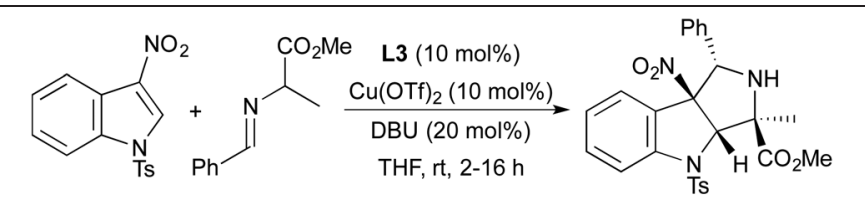

$1 \mathrm{a}$

\begin{tabular}{llllll}
\hline Entry & $\begin{array}{l}\text { Cu(II) } \\
\text { catalyst }\end{array}$ & $\begin{array}{l}\text { Time } \\
(\mathrm{h})\end{array}$ & $\begin{array}{l}\mathrm{dr} \\
\text { exo }^{\prime}: \text { exo }^{2} \text { endo }^{b}\end{array}$ & $\begin{array}{l}\mathrm{NMR}_{\mathrm{Nield}}^{b}(\%) \\
\text { yield }^{b}\end{array}$ & $\begin{array}{l}\text { ee } \\
\text { exo }^{\prime}-3 \mathbf{a}^{c}(\%)\end{array}$ \\
\hline 1 & Yes & 2 & $69: 5: 26$ & $84(91)$ & 87 \\
2 & No & 2 & $59: 6: 35$ & $49(52)$ & - \\
3 & Yes & 6 & $77: 9: 14$ & $99(99)$ & 90 \\
4 & No & 6 & $61: 10: 30$ & $78(82)$ & - \\
5 & Yes & 16 & $93: 3: 4$ & $99(99)$ & 89
\end{tabular}

${ }^{a}$ Catalysed reaction conditions: $1 \mathrm{a}(0.20 \mathrm{mmol})$, rac-2a $(0.24 \mathrm{mmol})$, $\mathrm{Cu}(\mathrm{OTf})_{2}(0.02 \mathrm{mmol}), \mathrm{L} 3(0.02 \mathrm{mmol}), \mathrm{DBU}(0.04 \mathrm{mmol})$, THF (1.0 mL), 2-16 h. ${ }^{b}$ Determined by ${ }^{1} \mathrm{H}$ NMR spectroscopy of the crude reaction mixture using dibromomethane as an internal standard. Conversion of 1a is listed in parentheses. ${ }^{c}$ Determined by chiral HPLC analysis after purification of $e x o^{\prime}-3 \mathbf{a}$ by column chromatography. Isolated yields of $e x o^{\prime}-3$ a were $65 \%$ (entry 1), $75 \%$ (entry 3), and $75 \%$ (entry 5). sion over the same time periods (entries 2 and 4). Although the uncatalyzed background reaction is slower than the catalyzed process, this data shows that the rate of uncatalyzed cycloaddition is sufficient to negatively impact the enantioselectivity of the cycloadditions and likely explains the poor enantioselectivity observed when the catalyst loading is lowered.

The evolution of diastereoselectivity over time is greatly influenced by the presence or absence of the copper catalyst. The uncatalyzed model reaction forms a 59:6:35 ratio of exo' exo: endo diastereomers after $2 \mathrm{~h}$, and this ratio does not change significantly over an additional $4 \mathrm{~h}$ (Table 2 , entries 2 and 4). In contrast, the diastereoselectivity of the copper-catalyzed cycloaddition changes markedly with reaction time. The catalyzed reaction forms a $69: 5: 26$ ratio of exo' : exo : endo diastereomers after $2 \mathrm{~h}$ (entry 1); a ratio that is similar to that observed in the uncatalyzed reaction. However, the diastereomeric ratio improves to $77: 9: 14$ (entry 3) after $6 \mathrm{~h}$ and to $93: 3: 4$ (entry 5) after $16 \mathrm{~h}$. The dramatic decrease in the amount of endo-3a and increase in the amount of exo'-3a indicates that the complex generated from $\mathrm{Cu}(\mathrm{OTf})_{2}$ and $\mathbf{L 3}$ catalyzes the epimerization of endo-3a to $e x o^{\prime}-3 \mathbf{a}$ which leads to the high $e x o^{\prime}$ selectivity of the cycloaddition reaction.

With a practical set of reaction conditions and a diastereoand enantioselective catalyst identified, we evaluated cycloadditions of $N$-tosyl-3-nitroindole $1 \mathrm{a}$ with a variety of imino esters $\mathbf{2} \mathbf{b}-\mathbf{k}$ derived from alanine methyl ester and an array of aromatic aldehydes. Results of these reactions are summarized in Table 3. In general, cycloadditions of 1a with imino esters containing 4-substituted aryl groups occur to form exo'-3 in $>70 \%$ yield with $>90 \%$ ee and $>90: 7: 3$ exo':exo:endo diastereoselectivity (entries 1-5). The notable exceptions to these typical yields and selectivities include the reactions of imino esters $2 \mathbf{b}\left(\mathrm{Ar}=4-\mathrm{F}_{3} \mathrm{CC}_{6} \mathrm{H}_{4}\right)$ and $2 \mathbf{c}\left(\mathrm{Ar}=4-\mathrm{ClC}_{6} \mathrm{H}_{4}\right)$. The cycloaddition of $\mathbf{2} \mathbf{b}$ with $\mathbf{1 a}$ occurs in high yield with excellent diastereoselectivity (entry 1). However, exo'-3b is isolated with $80 \%$ ee, possibly due to a faster rate of uncatalyzed background reaction with an azomethine ylide containing an electron-withdrawing 4-trifluoromethyl group on the arene moiety. This hypothesis is supported by a positive correlation between enantioselectivity of the reaction and increasing electrondonating ability of substituents at the 4-position on the aryl ring of the dipoles. The cycloaddition of 2c with 1 a forms exo'-3b in $70 \%$ yield with $88 \%$ ee, but the reaction occurs with modest diastereoselectivity (entry 2).

Cycloadditions of imino esters $2 \mathbf{g}-\mathbf{k}$ containing 2 - and 3-substituted aryl groups with 1a generally occur with slightly lower yields and selectivities (entries 6-10) than imino esters 2b-f. While the cycloaddition of $3-\mathrm{MeO}$-substituted imino ester $2 \mathbf{g}$ occurs to form $e^{2} o^{\prime}-\mathbf{3 g}$ in high yield with high diastereo- and enantioselectivity (entry 6), the cycloaddition of 3 -Br-substituted imino ester $\mathbf{2 h}$ formed exo' $^{\prime}-3 \mathbf{h}$ in only $40 \%$ yield with modest diastereoselctivity, likely due to a relatively slow epimerization of endo-3g to exo'-3g, and slightly lower enantioselectivity (entry 7). Cycloadditions of 2-MeO-, 2-F-, and 2-Cl-substituted imino esters $2 \mathbf{i}-\mathbf{k}$ formed exo $^{\prime}-3 \mathbf{i}-\mathbf{k}$ in $39-85 \%$ 
Table 3 Scope of dearomative cycloadditions of indole $1 \mathrm{a}$ with imino esters $2 \mathbf{b}-\mathbf{k}^{\mathrm{a}}$

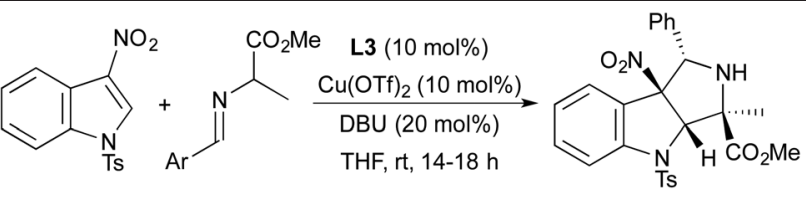

$1 \mathrm{a}$

rac-2b-k

exo'-3b-3k

\begin{tabular}{|c|c|c|c|c|c|}
\hline Entry & rac-2 (Ar) & $e x o^{\prime}-3$ & $\begin{array}{l}\mathrm{dr} \\
\text { exo } o^{\prime}: \text { exo }: \text { endo }\end{array}$ & Yield $e x o^{\prime}-3^{c}(\%)$ & $\begin{array}{l}\text { exo }-3^{d}(\%) \\
\text { ex }\end{array}$ \\
\hline 1 & $2 \mathbf{b}\left(4-\mathrm{F}_{3} \mathrm{CC}_{6} \mathrm{H}_{4}\right)$ & $3 \mathbf{b}$ & $>98: 1: 1$ & 83 & 80 \\
\hline 2 & $2 \mathrm{c}\left(4-\mathrm{ClC}_{6} \mathrm{H}_{4}\right)$ & $3 c$ & $78: 5: 17$ & 70 & 88 \\
\hline 3 & $2 d\left(4-\mathrm{BrC}_{6} \mathrm{H}_{4}\right)$ & $3 d$ & $95: 4: 1$ & 78 & 90 \\
\hline 4 & $2 \mathrm{e}\left(4-\mathrm{H}_{3} \mathrm{CC}_{6} \mathrm{H}_{4}\right)$ & $3 e$ & $90: 7: 3$ & 76 & 91 \\
\hline 5 & $2 f\left(4-\mathrm{MeOC}_{6} \mathrm{H}_{4}\right)$ & $3 f$ & $95: 4: 1$ & 71 & 96 \\
\hline 6 & $2 \mathrm{~g}\left(3-\mathrm{MeOC}_{6} \mathrm{H}_{4}\right)$ & $3 g$ & $89: 8: 3$ & 72 & 89 \\
\hline 7 & $2 \mathbf{h}\left(3-\mathrm{BrC}_{6} \mathrm{H}_{4}\right)$ & $3 h$ & $69: 8: 23$ & 40 & 80 \\
\hline 8 & $2 \mathbf{i}\left(2-\mathrm{MeOC}_{6} \mathrm{H}_{4}\right)$ & $3 \mathbf{i}$ & $74: 7: 19$ & 39 & 82 \\
\hline 9 & $2 \mathbf{j}\left(2-\mathrm{FC}_{6} \mathrm{H}_{4}\right)$ & $3 \mathbf{j}$ & $67: 5: 27$ & 51 & 87 \\
\hline 10 & $2 \mathbf{k}\left(2-\mathrm{ClC}_{6} \mathrm{H}_{4}\right)$ & $3 \mathbf{k}$ & $88: 8: 4$ & 85 & 79 \\
\hline
\end{tabular}

${ }^{a}$ Reaction conditions: 1a $(0.20 \mathrm{mmol}), 2(0.24 \mathrm{mmol}), \mathrm{Cu}(\mathrm{OTf})_{2}(0.02 \mathrm{mmol}), \mathrm{L} 3(0.02 \mathrm{mmol}), \mathrm{DBU}(0.04 \mathrm{mmol}), \mathrm{THF}(1.0 \mathrm{~mL}), 14-18 \mathrm{~h}$. ${ }^{b}$ Determined by ${ }^{1} \mathrm{H}$ NMR spectroscopy of the crude reaction mixture. ${ }^{c}$ Isolated yield of exo'-3a with $>95: 5$ dr. ${ }^{d}$ Determined by chiral HPLC analysis.

yield with $79-87 \%$ ee and with diastereoselectivities ranging from $67: 5: 27$ to $88: 8: 4$ exo' $:$ exo $:$ endo (entries 8-10).

The absolute configuration of exo'-3f was determined after treatment with $\mathrm{HBr}$ to form exo'-3f-HBr in $>99 \%$ yield (Scheme 2). The absolute configuration of exo'-3f.HBr was determined to be $(1 S, 3 R, 3 \mathrm{a} S, 8 \mathrm{~b} S)$ by X-ray crystallographic analysis.

Although our studies focused on reactions of $\mathrm{N}$-tosyl-3nitroindole 1a with imino esters derived from alanine methyl ester, we have also demonstrated that cycloadditions involving an imino ester derived from alanine isopropyl ester and
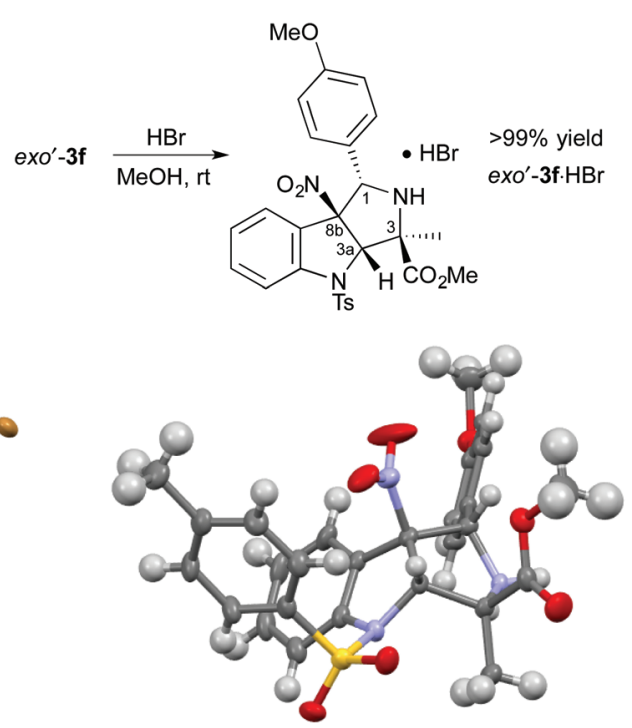

Scheme 2 Determination of the absolute stereochemistry of exo'-3f.
$N$-tosyl-5-bromo-3-nitroindole occur in high yields with excellent stereoselectivity (Scheme 3). For example, the reaction of $\mathrm{N}$-tosyl-3-nitroindole $\mathbf{1 a}$ with imino ester $\mathbf{2 l}$ derived from alanine isopropyl ester occurs with 93:7 exo' : exo diastereoselectivity and forms pyrroloindoline $e x o^{\prime}-31$ in $71 \%$ yield with $94 \%$ ee (Scheme 3a). The endo diastereomer was not observed after the $18 \mathrm{~h}$ reaction time. The cycloaddition of imino ester 2a with $N$-tosyl-5-bromo-3-nitroindole 1b occurs with nearly perfect exo' selectivity ( $>98: 1: 1$ exo' : exo : endo, Scheme $2 \mathrm{~b}$ ). Pyrroloindoline exo'-3m was isolated in $79 \%$ yield with $91 \%$ ee.
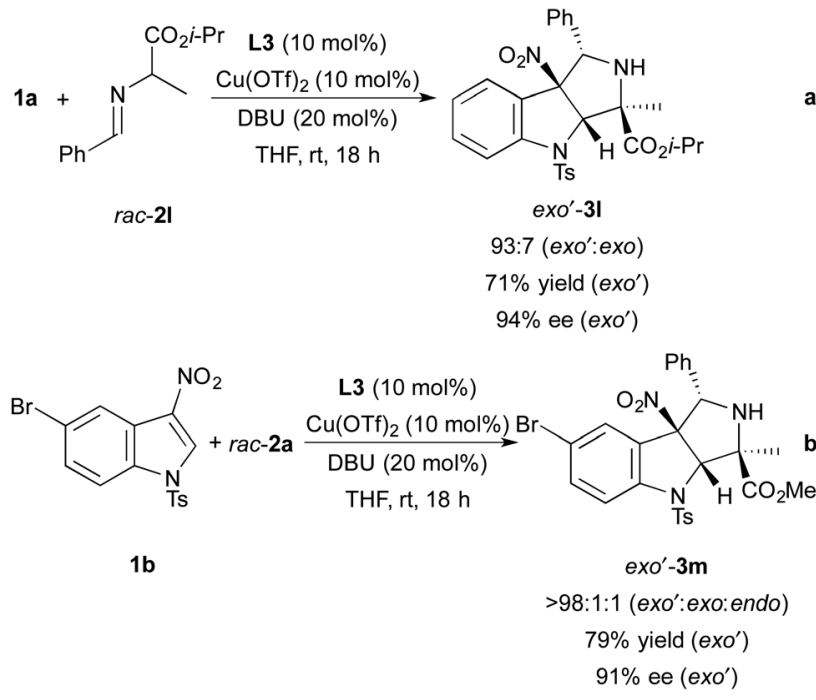

Scheme 3 Dearomative cycloadditions of indole 1a with imino ester rac-2l and indole $\mathbf{1 b}$ with imino ester rac-2a. 


\section{Conclusions}

In summary, we have developed the first catalytic, enantioselective dearomative cycloadditions of alanine-derived imino esters with 3-nitroindoles. These exo'-selective dearomative cycloadditions form a variety of highly enantioenriched pyrroloindolines with four contiguous stereogenic centers, two of which are fully substituted, when the reactions are conducted in the presence of a catalyst generated from $\mathrm{Cu}(\mathrm{OTf})_{2}$ and $(R)$ difluorphos. The high diastereoselectivities observed favoring the formation of the exo'-cycloadduct result from a $\mathrm{Cu}(\mathrm{OTf})_{2} /$ $(R)$-difluorphos-catalyzed epimerization of the endo-cycloadduct to the $e x o^{\prime}$-cycloadduct during the course of the reaction. Studies to develop new catalytic, enantioselective dearomative cycloadditions with additional classes of aromatic and heteroaromatic dipolarophiles are ongoing in our laboratory.

\section{Acknowledgements}

We thank Iowa State University and the Iowa State University Center for Catalysis for financial support of this work. We thank Dr Akady Ellern (ISU) for X-ray diffraction data collection and structure determination.

\section{Notes and references}

1 For reviews, see: (a) C.-X. Zhuo, W. Zhang and S.-L. You, Angew. Chem., Int. Ed., 2012, 51, 12662; (b) S. P. Roche and J. A. Porco Jr., Angew. Chem., Int. Ed., 2011, 50, 4068; (c) J. M. Keane and W. D. Harman, Organometallics, 2005, 24, 1786; (d) A. R. Pape, K. P. Kaliappan and E. P. Kündig, Chem. Rev., 2000, 100, 2917.

2 (a) M. Jia, M. Monari, Q. Yang and M. Bandini, Chem. Commun., 2015, 51, 2320; (b) D. Zhau, J. Zhang and Z. Xie, J. Am. Chem. Soc., 2015, 137, 9423; (c) L. Zhang, J. Am. Chem. Soc., 2005, 127, 16804.
3 For selected examples, see: (a) C. Venkatesh, P. Singh, H. Ila and H. Junjappa, Eur. J. Org. Chem., 2006, 5378; (b) J. Zhang, Z. Chen, H. Wu and J. Zhang, Chem. Commun., 2012, 48, 1817; (c) T. Miura, Y. Funakoshi and M. Murakami, J. Am. Chem. Soc., 2014, 136, 2272; (d) M. Yonekawa, Y. Koyama, S. Kuwata and T. Takata, Org. Lett., 2012, 14, 1164; (e) B. M. Trost, V. Ehmke, B. M. O'Keefe and D. A. Bringley, J. Am. Chem. Soc., 2014, 136, 8213; $(f)$ H. Li, R. P. Hughes and J. Wu, J. Am. Chem. Soc., 2014, 136, 6288; (g) H. Xiong, H. Xu, S. Liao, Z. Xie and Y. Tang, J. Am. Chem. Soc., 2013, 135, 7851; (h) L. M. Repka, J. Ni and S. E. Reisman, J. Am. Chem. Soc., 2010, 132, 14418; (i) J. Barluenga, E. Tudela, A. Ballesteros and M. Tomás, J. Am. Chem. Soc., 2009, 131, 2096; (j) A. Acharya, D. Anumandla and C. S. Jeffrey, J. Am. Chem. Soc., 2015, 137, 14858; (k) M. C. DiPoto, R. P. Hughes and J. Wu, J. Am. Chem. Soc., 2015, 137, 14861; $(l)$ H. Li, R. P. Hughes and J. Wu, J. Am. Chem. Soc., 2014, 136, 6288; (m) H. Li and J. Wu, Synthesis, 2015, 22.

4 (a) M. Kawano, T. Shoko, S. Negishi, H. Tanaka, T. Hoshikawa and J. Matsuo, Angew. Chem., Int. Ed., 2013, 52, 906; (b) N. Chopin, H. Gerard, I. Chataigner and S. R. Piettre, J. Org. Chem., 2009, 74, 1237; (c) M. Andreini, M. De Paolis and I. Chataigner, Catal. Commun., 2015, 63, 15.

5 G. Mei, H. Yuan, Y. Gu, W. Chen, L. Chung and C. Li, Angew. Chem., Int. Ed., 2014, 53, 11051.

6 For a review see: J. H. Ryan, ARKIVOC, 2015, 160.

7 S. Roy, T. L. S. Kishbaugh, J. P. Jasinski and G. W. Gribble, Tetrahedron Lett., 2007, 48, 1313.

8 (a) S. Lee, I. Chataingner and S. R. Piettre, Angew. Chem., Int. Ed., 2011, 50, 472; (b) S. Lee, S. Diab, P. Queval, M. Sebban, I. Chataingner and S. R. Piettre, Chem. - Eur. J., 2013, 19, 7181.

9 (a) A. Awata and T. Arai, Angew. Chem., Int. Ed., 2014, 53, 10462.

10 The formation of endo'-3a was not observed in cycloadditions of $1 \mathrm{a}$ and $2 \mathrm{a}$ catalyzed by complexes of $\mathrm{Cu}(\mathrm{OTf})_{2}$ and chiral bisphosphine ligands L1-L3.

11 A. M. Sarotti, R. A. Spanavello, A. G. Suárez, G. A. Echeverría and O. E. Piro, Org. Lett., 2012, 14, 2556. 